\title{
Product obsolescence of cellular phone market in Indonesia: a consumer perspective
}

\author{
Rafika Maulia ${ }^{1 *}$ and Alin Halimatussadiah ${ }^{1}$ \\ ${ }^{1}$ Department of Economics, Faculty of Economics and Business, Universitas Indonesia, Indonesia
}

\begin{abstract}
Obsolescence leads to a shorter lifecycle of electronic products which results in generating more electronic waste (e-waste) and excessive use of natural resources to produce goods. It is basically a wearing out of technical or esthetical appliances. Unfortunately, there are only a few studies and data focused on the issue, especially in developing counties. The objective of this study is to show how the lifespan of cellular phone change overtime and to provide data about consumer behavior in the Indonesia's cellular phone market. A total of 1.030 respondents were recruited from online survey in 13 most populous cities of Indonesia for consumer analysis. Panel regression Common Effect Model (CEM) and Chi-squared independent test were applied as the analytical tools. The result shows that both consumer contribute to the reduction of cellular phone lifecycle. It is confirmed that the lifespan of cellular phone is getting shorter by the year and by the ownership order. In addition, subjective considerations of discarding product significantly reduce cellular phone's lifespan. Obsolescence is not only an issue that should be addressed to the manufacturers, but also as a responsibility for the consumers.
\end{abstract}

\section{Introduction}

E-waste is a set of electronic and electrical equipment (EEE) alongside with their components that has been disposed by the owner without any desire for further reutilization. E-waste is increasing among developing countries following people's income amelioration as an implication of the considerate economic growth rapidity [1]. United Nation University ViE - SCYCLE found that within 2010 to 2015, the growth of e-waste in developing countries reached $65 \%$. In East and South-east Asia, the rise of e-waste amounted to $62.7 \%$. Meanwhile, Indonesia ranks first as the highest e-waste generator in South-east Asia with 68\% growth [2]. This fact possesses a big problem in sustainability aspect, especially in consumption, production, and resource utilization.

The increase in e-waste volume, among others, is one of the consequences of a product obsolescence phenomenon. Product obsolescence leads to a shorter lifecycle of various electronic products. Product obsolescence occurs in parallel to changes in society's consumption pattern and the producers' strategy to improve the scale of their companies, which accordingly shorten the lifespan of products $[3,4,5]$. Furthermore, factors that propel

${ }^{*}$ Corresponding author: rafikamauliaa@gmail.com 
the shortening of products' lifespan include the speed of trends and taste shift among societies and rapid technological enhancement [6].

In general, Packard (1960) classifies product obsolescence into three types, quality obsolescence (material) which refers to low material qualities used; functional obsolescence, the implication of technological improvement that enhance products' functions diversity and resources efficiency; and desirability-driven obsolescence or psychological obsolescence, occurs because of consumers' subjective assessment [5, 6, 7]. In his subsequent studies, Cooper (2004) widens the classification by adding a new obsolescence type, which is the economic obsolescence as a form of products' performance comparison or the price ratio with their alternative products. Apart from the four types of product obsolescence as mentioned above, Granberg (1997) also divides product obsolescence into two types; "absolute obsolescence" where products are in absolute damage and no longer usable and "relative obsolescence" where products are already disposed despite of their remaining usage capacity [8].

Cooper (2004) conducted a research on consumer behavior regarding product obsolescence on a myriad of electronic equipment and found that a product lifespan is largely influenced by relative obsolescence compared to absolute obsolesce. The study also found that cellular phones and computer equipment are the highest among other electronic products to be influenced by functional/technological obsolescence. A research done by Wang et al. (2013) in the Netherlands reveals a decline in the average lifespan of EEE from 2000 to 2005 [9]. Moreover, $\mathrm{Li}$ (2005) found that there was a significant increase in cellular phone disposal volume in China in a decade since 2002 [10].

Although the product obsolescence phenomenon is incrementally visible, the data provided in support for this issue are highly limited, especially in developing countries such as Indonesia. For this reason, this study aims to discover how products' lifespan alters overtime and to provide data on consumer behavior in Indonesia's cellular phone market.

\section{Method}

Online survey method is utilized to capture the pattern of consumer behavior in using cellular phones. The consumer population in this research is residents in 12 most populous cities in Indonesia and with the addition of one megacity area, which is the Jabodetabek (13 regions in total). There are 1,030 respondents of total samples with 95\% Confidence Level and $3.1 \%$ margin of error. Non-probability sampling is applied as the sampling method, specifically the purposive sampling.

The data are analyzed with a regression method using Common Effect Model (CAM) approach or commonly known as Pooled Least Square (PLS). The data assembled from the survey are a panel data with unbalanced panel data type-with 3,509 observations for Regression Model 1 and 2 and 1,802 observations for Regression Model 3 (952 respondents in total after data validation). The data are unbalanced for the existence of many varieties of phones owned by each respondent - where in this research accounted as time series.

There are three model specifications that are used, as written below:

Model 1:

$$
y_{i t}=\beta_{0}+\beta_{1} X_{1 i t}+\beta_{2} X_{2 i t}+\beta_{3} X_{2 i t}+\beta_{4} X_{4 i t}+\beta_{5} X_{5 i t}+\beta_{6} X_{6 i t}+\beta_{7} X_{7 i t}+\varepsilon_{i t}
$$

Model 2:

$$
\begin{aligned}
& y_{i t}=\beta_{0}+\beta_{1} X_{1 i t}+\beta_{2} X_{2 i t}+\beta_{3} X_{2 i t}+\beta_{4} X_{4 i t}+\beta_{5} X_{5 i t}+\beta_{6} X_{6 i t}+\beta_{7} X_{7 i t}+\beta_{8} X_{8 i t}+ \\
& \beta_{9} X_{9 i t}+\beta_{10} X_{10 i t}+\varepsilon_{i t}
\end{aligned}
$$


Model 3:

$$
\begin{gathered}
y_{i t}=\beta_{0}+\beta_{1} X_{1 i t}+\beta_{2} X_{2 i t}+\beta_{3} X_{2 i t}+\beta_{4} X_{4 i t}+\beta_{5} X_{5 i t}+\beta_{6} X_{6 i t}+\beta_{7} X_{7 i t}+\beta_{8} X_{8 i t}+ \\
\beta_{9} X_{9 i t}+\beta_{10} X_{10 i t}+\beta_{11} X_{11 i t}+\varepsilon_{i t}
\end{gathered}
$$

Description:

$y_{i t}=$ cellular phone's lifespan

$\beta_{0}=$ intercept

$X_{1 i t}=$ cellular phone ownership order

$X_{2 i t}=$ cellular phone ownership order squared

$X_{3 i t}=$ year of cellular phone ownership

$X_{4 i t}=$ age

$X_{5 i t}=\operatorname{sex}$

$X_{6 i t}=$ economic status

$X_{7 i t}=$ environmental awareness index

$X_{8 i t}=$ material obsolescence

$X_{9 i t}=$ functional obsolescence

$X_{10 i t}=$ psychological obsolescence

$X_{11 i t}=$ cellular phone price

$\varepsilon_{i t}=$ error

$\mathrm{i}=\mathrm{i}$-th individual $(1,2, \ldots, \mathrm{n})$

$\mathrm{t}=\mathrm{t}$-th cellular phone ownership order $\left(1^{\text {st }}\right.$ phone, $2^{\text {nd }}$ phone, $, \ldots, \mathrm{t}$-th phone $)$

\section{Results}

Below are the results of regression estimation using Pooled Least Square (PLS) to capture consumer's behavior on the use of cellular phone.

Table 1. The Regression Model Estimation Results with Pooled Least Square (PLS)

\begin{tabular}{|l|l|l|l|}
\hline Variable & Model 1 & Model 2 & Model 3 \\
\hline Cellular Phone Ownership Order & $0.210^{* *}$ & $0.219^{* *}$ & $1.132^{* * *}$ \\
\hline Cellular Phone Ownership Order & $-0.032^{* *}$ & $-0.032^{* *}$ & $-0.197^{* * *}$ \\
\hline $\begin{array}{l}\text { Year of Cellular Phone } \\
\text { Ownership }\end{array}$ & $-0.134^{* * *}$ & $-0.137^{* * *}$ & $-0.107^{* * *}$ \\
\hline Age & $0.013^{* * *}$ & $0.014^{* * *}$ & $0.010^{* *}$ \\
\hline Sex & 0.052 & $0.092^{*}$ & 0.081 \\
\hline Social Economic Status & $-0.085^{*}$ & $-0.086^{*}$ & -0.074 \\
\hline Environmental Awareness Index & 0.242 & 0.295 & $0.473^{*}$ \\
\hline Material Obsolescence & & 0.001 & 0.012 \\
\hline Functional Obsolescence & & -0.062 & -0.088 \\
\hline Psychological Obsolescence & & $-0.197^{* * *}$ & $-0.203^{* *}$ \\
\hline Cellular Phone Price & & & $0.061^{* *}$ \\
\hline Constant & $3.779 * * *$ & $3.836^{* * *}$ & $2.567^{* * *}$ \\
\hline
\end{tabular}

Description:

1. $* * *, * *, *$ refer to $1 \%, 5 \%$, and $10 \%$ significant level respectively.

2. $\mathrm{R}^{2}$ for Model 1 is $12.3 \%$, Model 2 is $11.9 \%$, and Model 3 is $9.9 \%$

3. Global test for goodness of fit (Wald Test) is significant in $1 \%$ level for all three models.

4. Breusch-Pagan Test and White Test for heteroscedasticity shows p-value < 0.05 for all three models (the existence of heteroscedasticity problem). 
5. All models use Robust Standard Error for eliminating heteroscedasticity.

As the estimations are revealed, here are some remarkable findings:

- Cellular phone's lifespan has declined with increasing years, where cellular phones are currently used shorter than the previous one.

- Based on the cellular phone ownership order, cellular phone's lifespan in Indonesia follows a quadratic pattern (inverted U curve), where the first cellular phone will have a shorter lifespan than the next cellular phone. The lifespan of the following ones remains increasing until at a certain point of cellular phone ownership order, the lifespan declines.

- Psychological obsolescence negatively affects the cellular phone's lifespan. This finding implies that the decisions of consumers to purchase and use cellular phones are largely influenced by subjectivity factors.

- There is no association between individual's environmental awareness level with cellular phone's lifespan.

- The price level is positively associated with cellular phone's lifespan. Phones with higher price tend to be used longer by consumers.

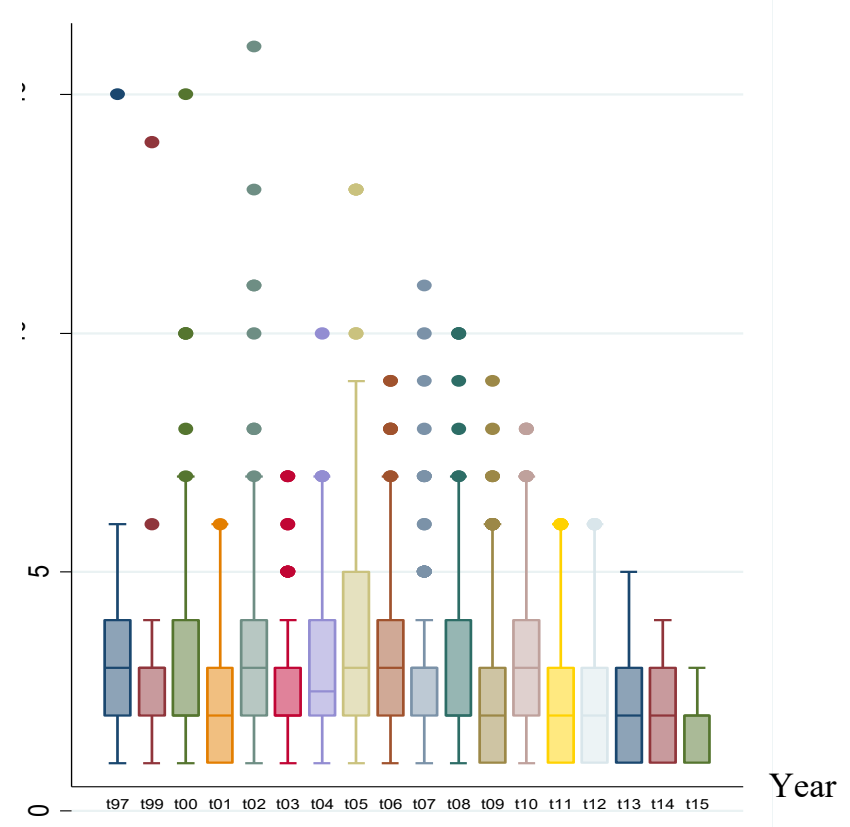

Figure 1. Cellular Phone's Lifespan, 1997-201

Boxplot in Figure 1. shows that cellular phone's lifespan is continuously decreasing from 1997 to 2015. Maximum lifespan is conspicuously waning each year, alongside with the decline in cell phone's lifespan average and median.

\section{Conclusion}

Empirically, it is proven that cellular phone's lifespan in Indonesia is facing a decline over the years. This fact indicates the increase in cellular phones consumption because of high product turnover. Consumers are encouraged by various motivations to frequently change 
their cellular phones, where individual subjective assessment on a product becomes a crucial point in consumption related decision-making process. Product turnover that occurs rapidly will lead to the rise of uncontrollable e-waste volume. If the waste produced exceeds the environmental carrying capacity, this condition certainly reveals a potential adverse effect environmentally. Thus, a policy and action should be taken to overcome this issue. A sustainable consumption and production system should be proposed to enable a better resource and waste management.

\section{References}

1. R. Shah, Waste statistic (United Nations Environment Programme, Addis Ababa, 2007)

2. S. Honda, D. S. Khetriwal, R. Kuehr, Regional e-waste monitor: east and southeast asia (United Nations University ViE - Sustainable Cycles, Bonn, 2016)

3. G. Bodenstein, H. Leuer, J. Cons. Pol. 5, 29-50 (1981)

4. C. P. Bakker, F. Wang, R. Kuehr, J. Huisman, J. Clean Prod. 69, 10-16 (2014)

5. L. Hennies, R. Stamminger, Resrc. Conserv. and Rcyc. 112, 78-82 (2016)

6. T. Cooper, J. Cons. Pol. 27, 421-449 (2004)

7. K. Pope, Understanding planned obsolescence: unsustainability through production, consumption and waste generation (Kogan Page Publisher, London, 2017)

8. B. Granberg, The quality re-evaluation process: product obsolescence in a consumerproducer interaction framework (Department of Economic History University of Stockholm, Stockholm, 1997)

9. F. Wang, J. Huisman, A. Stevels, C. P. Balde, Waste Man. 33, 2397-2407 (2013)

10. B. Li, J. Yang, B. Lu, X. Song, Waste Man. 35, 247-254 (2015) 